\title{
ESPECTRÔMETRO POR ULTRA-SOM: VIABILIDADE COMO ANALISADOR FÍSICO-QUIMICA DO LEITE
}

\section{SPECTOMETER ULTRASOUND: AVAILABILITY AS PHYSICAL- CHEMISTRY ANALYSER FOR MILK}

\author{
Lúcia Felicidade Dias ${ }^{1}$; Marly Sayuri Katsuda ${ }^{2}$; Reginaldo Fidelis ${ }^{2}$; Yuna Miyuki Takaki ${ }^{3}$; Karina \\ Yamazaki $^{3}$; Deise Sanae Yamamoto ${ }^{3}$ \\ ${ }^{1,2}$ Universidade Tecnológica Federal do Paraná - UTFPR - Londrina - Brasil lfdias@ utfpr.edu.br \\ ${ }^{3}$ Universidade Tecnológica Federal do Paraná - UTFPR - Londrina - Brasil yuna takaki@ hotmail.com
}

\begin{abstract}
Resumo
O presente estudo teve como objetivo avaliar o desempenho do espectrômetro por ultra-som, o Lactoscan Milk Analyser da empresa Milkotronic, na caracterização físico-quimica de amostras de leite com diferentes teores de gordura. O desenvolvimento do trabalho consistiu na padronização do teor de gordura do leite 'in natura' nos teores de 1 e 3\% (p/p). Foram avaliados os seguintes parametros: índice crioscópio, densidade, extrato seco desengordurado, lactose, proteína, cinzas e gordura. Para avaliar esses parâmetros adotou o método oficial publicado pela legislação vigente para leite 'in natura'. Os resultados demonstraram que o teor de gordura influencia na capacidade do equipamento em determinar alguns parâmetros. Em leite desnatado, o equipamento determinou os parâmetros extrato seco desengordurado, proteínas e cinzas diferente estaticamente ao método oficial. Por outro lado, amostras de leite com 3\% de gordura, demonstraram que o equipamento determinou parâmetros de índice crioscópio, densidade e gordura estatisticamente diferente no nível de $5 \%$ de significância em relação ao método oficial. Os resultados demonstraram que há necessidade de realizar mais repetições deste estudo para obter conclusões seguras.
\end{abstract}

Palavras-chave: teor de gordura, método oficial, parâmetro legal.

\section{Introdução}

De acordo com a Instrução Normativa n. 51 do Ministério da Agricultura, Pecuária e Abastecimento (BRASIL, 2002), pode-se entender por leite, o produto oriundo de uma ordenha completa, ininterrupta sob condições de higiene, de vacas sadias e bem alimentadas e descansadas. O leite é uma mistura homogênea de grande número de substâncias (lactose, glicerídeos, proteínas, sais, vitaminas, enzimas, etc.), das quais algumas então em emulsão, algumas em suspensão e outras em dissolução. A qualidade do leite como alimento e matéria-prima para a indústria de laticínios dependem de sua composição nutritiva e qualidade microbiológica (MARTINS, 2006). 
O conhecimento de sua composição química é de suma importância para a fabricação de produtos lácteos fermentados ou não (VENTUROSO, 2007). Componentes como gordura, proteínas, carboidratos e em maior proporção, a água onde estão dispersos os demais compostos. Há presença de substâncias minerais e traços de enzimas, naturais ou provenientes de microrganismos, em pequenas quantidades. A composição do leite pode variar de forma significativa de acordo com a espécie, devendo ser considerado a raça, a idade, o estado de saúde, sua alimentação, número de ordenhas diárias, período de lactação e estado nutricional (TRONCO , 2008).

A composição química do leite deve ser analisada na plataforma de laticínios e estes devem apresentar seus requisitos físico-quimicos dentro dos padrões mínimos exigidos pela normativa publicado no Ministério da Agricultura para sua transformação em produtos lácteos (Tabela 1).

Tabela 1 - Requisitos físico-químicos do leite cru refrigerado

\begin{tabular}{cc}
\hline Requisitos & Limites \\
Matéria - gorda $\left(\mathrm{g} .100 \mathrm{~g}^{-1}\right)$ & Mínimo de 3,0 \\
Densidade relativa a $15^{\circ} \mathrm{C}\left(\mathrm{g} \cdot \mathrm{mL}^{-1}\right)$ & 1,028 a 1,034 \\
Acidez titulável $\left(\mathrm{g}\right.$ de ácido láctico. $\left.100 \mathrm{~mL}^{-1}\right)$ & 0,14 a 0,18 \\
Extrato seco desengordurado $\left(\mathrm{g} \cdot 100 \mathrm{~g}^{-1}\right)$ & mín. 8,4 \\
Índice Crioscópico & Máximo $-0,530^{\circ} \mathrm{H}$ \\
Proteínas $\left(\mathrm{g} .100 \mathrm{~g}^{-1}\right)$ & (equivalente a $\left.-0,512^{\circ} \mathrm{C}\right)$ \\
\hline
\end{tabular}

Fonte: BRASIL, 2002.

De acordo com Zafalon (2011), uma boa qualidade do leite depende das condições higiênicas de obtenção e manejo do leite até a plataforma de recepção, bem como é necessário análises periódicas da composição do leite, para avaliar as condições de conservação do leite e indiretamente a qualidade microbiológica e sanidade animal. Tronco (2006) menciona que a água utilizada durante o processamento é de fundamental importância para se ter um produto de qualidade, e que em $95 \%$ dos estudos já realizados a contaminação pode ser consequente da deficiencia na limpeza dos equipamentos e utensílios, falta de higiene durante a ordenha e estocagem em temperaturas inadequadas.

As análises físico-química do leite recomendadas pelo Ministério da Agricultura e Pecuária (MAPA) são baseados no princípio de destruição das amostras, além do custo dos reagentes devido a qualidade de pureza absoluta (PA), necessidade de investir em corpo técnico especializado e tempo prolongado para conclusão das análises. Com isso torna-se necessário o desenvolvimento de técnicas e instrumentos que realizam análises rápidas, precisas e confiáveis. Um dos equipamentos que tem ganhado destaque nas plataformas de recepção é espectrômetro por ultra-som ou conhecido como analisador de leite por ultra-som. Esta técnica vem sendo difundido cada vez mais na 
indústria de alimentos, pois estes equipamentos avaliam as propriedades físico-químicas, tais como composição, estrutura, estado físico e taxa de fluxo dos alimentos (McCLEMENTS, 1995). O princípio do equipamento consiste na utilização de ondas de som com frequência extremamente alta. A velocidade das ondas de ultra-som em solução com maior quantidade de sólidos solúveis e concentração de água, proporciona um aumento da velocidade do som. Por outro lado, amostras com elevado teor de gordura reduz a velocidade do som (VENTUROSO et al., 2007). As análises não são destrutivas a amostra, levando de um minuto ou menos para a análise.

De acordo com BUCKIN (2003), em ondas ultra-sônicas, quando estas perdem energia por compressão ou descompressão, é caracterizado como atenuação, que ainda incluem absorção de espalhamento das ondas. Como medidas de atenuação não dependem da temperatura da amostra, pode-se fazer grande quantidade de análises. Já a velocidade ultra-sônica é determinada pela densidade e elasticidade do meio. E McClements (1997) cita a impedância acústica, como a determinação da fração de onda que é refletida na superfície da amostra.

Figura 1 - Principio do Espectrômetro por Ultra-som

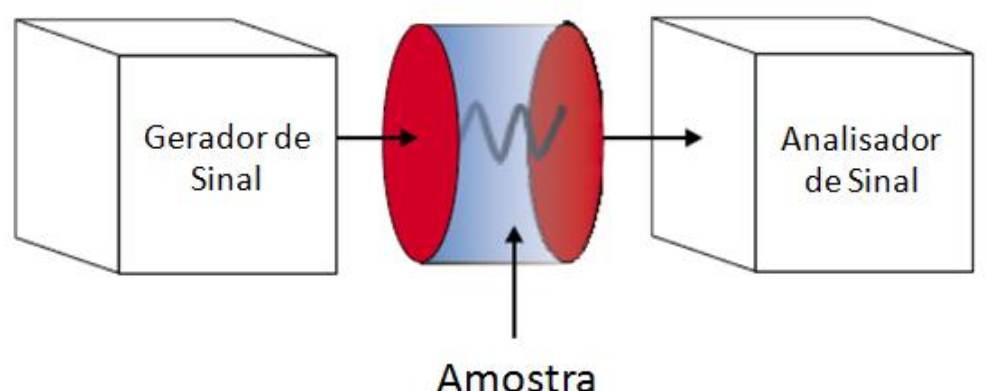

Fonte: Adaptado de Buckin, 2003.

Vários autores estudaram a aplicação da tecnologia ultrasônica para avaliar composição dos alimentos, crescimento microbiano, estado físico, estrutura e propriedades moleculares. O ultra-som oferece como vantagem um recurso rápido, não destrutivo e não invasivo para avaliar os produtos ou materiais. Além da sua aplicação em equipamentos laboratoriais, pode ser aplicado continuamente para monitorar propriedades dos alimentos durante seu processamento (McCLEMENTS, 1997, ELVIRA et al., 2005).

Deste modo o presente artigo tem a finalidade de avaliar o desempenho do espectrômetro por ultra-som comparado ao método oficial em amostras de leite 'in natura' com diferentes teores de gordura. 


\section{Material e Métodos}

As amostras analisadas foram adquiridas em fazenda produtora de leite tipo "A", localizada no distrito de Warta, próximo a cidade de Londrina-PR. Este estudo foi realizado durante o período de setembro a dezembro de 2010.

As amostras foram padronizadas quanto ao teor de gordura com as seguintes concentrações: 1,0 e 3,0 \% (p/p). Esta padronização ocorreu a partir do balanceamento do teor de gordura a partir de leite 'in natura' magro $(\sim 1,0 \%)$ e gordo $(\sim 15 \%)$, adotando o método de quadrado de Pearson (AMIOT, 1991). Estas amostras eram obtidas a partir do leite ordenhado mantido sob refrigeração, sem agitação, com o passar do tempo ocorria o afloramento da gordura. Deste modo, o leite gordo consistia na coleta de uma alíquota na parte superior do tanque de estocagem. Enquanto o leite com baixo teor de gordura era coletado na parte inferior do tanque. O teor de gordura foi determinada de acordo com a Instrução Normativa n.68 (BRASIL, 2006).

O estudo consistiu no preparo das amostras do leite com diferentes teores de gordura, em seguida foram realizadas análises físico-química de acordo com os requisitos exigidos pela legislação pelo método oficial. No primeiro dia eram realizadas as caracterizações fisico-químicas pelo analisador por ultra-som. As análises oficiais consistiram na determinação de compostos nitrogenados convertido em teor de proteína (P), Lactose (L), material lipídico (G), cinzas (C) extrato seco desengordurado (ESD), índice crioscópico (IC) e densidade (D), seguiram de acordo com a Instrução Normativa n.68 (BRASIL, 2006). Todas as análises oficiais foram feitas em triplicatas. A avaliação pelo espectrômetro por ultra-som foram realizadas em 9 replicatas.

O equipamento ultrasônico que foi utilizado no estudo é o modelo Lactoscan Milk Analyzer, da marca Milkotronic ${ }$, Bulgária, que determina 8 parâmetros físico-químicos: P, ESD, L, G, C e IC. O equipamento foi gentilmente cedido pela empresa ENTELBRA Indústria Eletrônica, localizado no município de Londrina - PR.

Os resultados de caracterização físico-química pelo método oficial e analisador ultrasônico foram avaliados quanto à distribuição normal e em caso positivo será realizado análise de variância (ANOVA) e as diferenças de médias entre os métodos por parâmetro físico-químico foram comparados adotando o teste de Tukey e correlação no nível de 5\% de significância. As análises estatística foram realizadas através do programa BioEstat, versão 5.0 (2007).

\section{Resultados e Discussão}

Os resultados da amostra com $1 \%$ de gordura analisada pelo analisador por ultra-som demonstrou alguns parâmetros diferentes estatisticamente no nível de $5 \%$ de significância comparado aos dados obtidos pelo método oficial (Tabela 2). 
Tabela 2 - Resultados das análises físico-quimicas de amostras com 1\% de gordura pelo método oficial comparado ao espectrômetro por ultra-som

\begin{tabular}{ccc}
\hline \multirow{2}{*}{ Parâmetro } & \multicolumn{2}{c}{ 1\% de Gordura } \\
\cline { 2 - 3 } & Análise oficial & Ultra-som \\
\hline Extrato Seco Desengordurado (\%) & $8,91 \pm 0,04^{\mathrm{a}^{\mathrm{a}}}$ & $8,52 \pm 0,03^{\mathrm{b}}$ \\
Indice Criosópio $\left({ }^{\circ} \mathrm{H}\right)$ & $-0,537 \pm 0,006^{\mathrm{a}}$ & $-0,528 \pm 0,002^{\mathrm{a}}$ \\
Densidade $\left(\mathrm{g} \cdot \mathrm{mL}^{-1}\right)$ & $1,032 \pm 0,000^{\mathrm{a}}$ & $1,032 \pm 0,000^{\mathrm{a}}$ \\
Proteína (\%) & $3,56 \pm 0,00^{\mathrm{a}}$ & $3,12 \pm 0,01^{\mathrm{b}}$ \\
Lactose $(\%)$ & $4,60 \pm 0,20^{\mathrm{a}}$ & $4,78 \pm 0,01^{\mathrm{a}}$ \\
Cinzas $(\%)$ & $0,73 \pm 0,01^{\mathrm{a}}$ & $0,71 \pm 0,00^{\mathrm{b}}$ \\
Gordura $(\%)$ & $1,00 \pm 0,00^{\mathrm{a}}$ & $1,02 \pm 0,02^{\mathrm{a}}$ \\
\hline
\end{tabular}

*a,b - letras minúsculas diferentes correspondem que os métodos apresenta diferença estatística no nível de $5 \%$ de significância.

Em amostras com reduzido teor de gordura demonstraram que afetam o desempenho do analisador por ultra-som. De acordo com os resultados obtidos pelo equipamento houve diferença significativa no nível de 5\% significância comparado ao valor obtido pelo método oficial. Este resultado foi similar ao observado por Venturoso et al. (2007), o qual analisou leite pasteurizado desnatado em dois perfis do programa do analisador por ultra-som de marca concorrente (Ekomilk), ou seja, cada perfil tratava-se da condição de análise para leite pasteurizado e 'in natura'. $\mathrm{O}$ resultado observado para este perfil demonstrou que o leite pasteurizado desnatado determinado em ambos os perfis, apresentou diferença significativa na primeira repetição. O mesmo foi observado por Ponsano et al. (2007), o qual analisou o teor de ESD de leite 'in natura' proveniente de várias vacas. Embora deve-se considerar que o presente estudo analisou amostra com teor de gordura menor do que o autor. Uma possível justificativa do resultado proporciona deduzir que o resultado obtido pelo espectrômetro por ultra-som é consequente de um cálculo realizado pelo equipamento, levando a determinar o resultado aproximado de cada parâmetro. Não determinando exatamente a concentração de alguns componentes do leite como ocorre pelo método oficial.

Os valores de índice crioscópio, densidade, teor de lactose e gordura demonstraram que o equipamento determina o valor similar ao método oficial. Apesar do estudo ter sido realizado uma única vez, necessitando de mais repetição, o equipamento demonstrou uma certa confiabilidade para determinar esses parametros. De acordo com Venturoso et al. (2007) o equipamento também demonstrou boa correlação para o teor de lipídeos. Ponsano et al. (2007) determinaram o mesmo desempenho no equipamento para os parâmetros de densidade, embora não tenha demonstrado uma boa correlação entre os métodos analíticos. Por outro lado, os autores obtiveram diferença significativa nos teores de gordura das amostras de leite crú determinado pelo ultro-som comparado ao método oficial. O que demonstra que cada equipamento tem um desempenho diferente devido a particularidade de cada fabricante. 
O teor de proteína e cinzas determinado pelo analisador por ultra-som demonstrou diferença significativa com os resultados obtidos pelo método oficial. Esse resultado condiz com o determinado por Ponsano et al. (2007), o qual concluiu que o equipamento não determinou os mesmos valores comparado ao método de referência.

Em amostras de leite 'in natura' com teor de gordura dentro dos limites exigido pela Instrução normativa n.51 (BRASIL, 2002), o qual requer que o leite para ser aceito na plataforma de recepção deve apresentar no mínimo 3\%, demonstrou diferenças significativas no nível de 5\% em outros parâmetros que não foi levantado em amostras com teor de gordura de 1\% (Tabela 3).

Tabela 3 - Resultados das análises físico-quimicas de amostras com 3\% de gordura pelo método oficial comparado ao espectrômetro por ultra-som

\begin{tabular}{ccc}
\hline Parâmetro & \multicolumn{2}{c}{ 3\% de Gordura } \\
\cline { 2 - 3 } & Análise oficial & Ultrasom \\
\hline Extrato Seco Desengordurado $(\%)$ & $8,77 \pm 0,06^{\mathrm{a}}$ & $8,64 \pm 0,06^{\mathrm{a}}$ \\
Indice Crioscópio $\left({ }^{\mathrm{o}} \mathrm{H}\right)$ & $-0,537 \pm 0,002^{\mathrm{b}}$ & $-0,549 \pm 0,005^{\mathrm{a}}$ \\
Densidade $\left(\mathrm{g} \cdot \mathrm{mL}^{-1}\right)$ & $1,031 \pm 0,000^{\mathrm{b}}$ & $1,033 \pm 0,001^{\mathrm{a}}$ \\
Proteína $(\%)$ & $3,19 \pm 0,00^{\mathrm{a}}$ & $3,17 \pm 0,02^{\mathrm{a}}$ \\
Lactose $(\%)$ & $4,87 \pm 0,06^{\mathrm{a}}$ & $4,74 \pm 0,03^{\mathrm{a}}$ \\
Cinzas $(\%)$ & $0,71 \pm 0,01^{\mathrm{a}}$ & $0,71 \pm 0,00^{\mathrm{a}}$ \\
Gordura $(\%)$ & $3,10 \pm 0,0^{\mathrm{a}}$ & $3,25 \pm 0,04^{\mathrm{b}}$ \\
\hline
\end{tabular}

a,b - letras minúsculas diferentes correspondem que os métodos apresenta diferença estatística no nível de $5 \%$ de significância.

Ao avaliar amostras de leite com teor de gordura superior demonstrou comportamento diferente comparado ao estudo com leite a $1 \%$ de gordura. $\mathrm{O}$ equipamento determinou os valores de extrato seco desengordurado, proteína, lactose e cinzas iguais ao encontrado pelo método oficial. Ponsano et al. (2007) concluiu que o equipamento conseguiu determinar somente o valor de densidade igual ao método oficial.

Por outro lado, o autor determinou diferença significativa nos parâmetros de extrato seco desengordurado, proteína e gordura. Neste estudo foi observado o mesmo desempenho do autor ao analisar o teor de gordura. O valor de índice crioscópico e densidade apresentaram diferença significativa no nível de 5\% para amostras com teor de gordura ao redor de 3\%. Embora a diferença do valor de densidade determinada seja consideralvelmente pequena.

\section{Conclusão}

O presente estudo permitiu observar que ao alimentar amostras de leite com diferentes teores de gordura, afeta a resposta do espectrômetro por ultra-som. Em amostras que apresentam 
problemas de desnate o equipamento determina parametros de Extrato seco desengordurado, proteínas e cinzas diferente do método oficial. Por outro lado, amostras de leite enquadrados ao limite legal, demonstraram que o equipamento determinou parâmetros de índice crioscópio, dendidade e gordura diferente do método oficial. A partir desse resultado permitiu concluir que necessita realizar mais repetições para obter resultados mais confiáveis.

\begin{abstract}
This study aimed to evaluate the performance of the spectrometer by ultrasound, Lactoscan Milk Analyser by Milkotronic company, to analyze physical-chemistry parameters of milk samples with different fat contents. The development work was to standardize the fat content of milk "in natura" in the contents of 1 and 3\% (w / w). We evaluated the following parameters: cryoscope index, density, defatted dry matter, lactose, protein, ash and fat. To evaluate these parameters were consulted the Brazilian official standard method for milk "in natura". The results showed that the fat content influences the spectrometer by ultrasound to determine some parameters. In skimmed milk, the equipment determined defatted dry matter, protein and ash statistically different than the official method. Moreover, milk samples with 3\% of fat, showed that the equipment determined cryoscope index, density and fat statistically different at 5\% level of significance than the official method. The results showed that need to perform more repetitions of this study to obtain reliable conclusions.
\end{abstract}

Key-words: fat, official method, legal parameter.

\title{
Referências
}

AMIOT. J. Ciência y Tecnologia de la leche. Ed. Acribia, S.A. Zaragoza, Espanha, 1991.

BRASIL, Ministério da Agricultura, Pecuária e Abastecimento. Instrução Normativa n ${ }^{\circ} 51$ de 18 de setembro de 2002. Aprova os Regulamentos Técnicos de Produção, Identidade e Qualidade do leite tipo A, do leite tipo B, do Leite tipo C, do leite Pasteurizado e do Leite Cru refrigerado e o Regulamento Técnico da Coleta de Leite Cru Refrigerado e seu Transporte a Granel. Publicado no Diário Oficial da União de 20 de setembro de 2002, Seção 1, Página 13.

BRASIL. Métodos Analíticos Oficiais Físico-Químicos, para controle de Leite e Produtos Lácteos. Instrução Normativa $\mathrm{n}^{\circ} 68$ de 12 de dezembro de 2006. Ministério da Agricultura da Pecuária e Abastecimento. Diário Oficial da República Federativa do Brasil, Brasília, 14 dez. 2006. Disponível em < http://extranet.agricultura.gov.br/sislegisconsulta/consultarLegislacao.do?operacao=visualizar\&id=17472>. Acesso em 04 abr 2011.

BUCKIN, V.; O’DRISCOLL, B.; SMYTH, C. Ultrasonic spectroscopy for material analysis: recent advances. Spectroscopy Europe., v.15, p.20-25, 2003

ELVIRA, L.; SAMPEDRO, L.; MATESANZ, J.; GOMEZ-ULLATE, Y.; RESA, P.; IGLESIAS, J.R.; ECHEVARRÍA, F. J.; MONTERO DE ESPINOSA, F. Non-invasive and non-destructive ultrasonic technique for the detection of microbial contamination in packed UHT Milk. Food Research International, n. 38, p. 631-638, 2005. DOI: 10.1016/j.foodres.2004.12.001

MARTINS, Lidia Santos Pereira. Monitoramento da produção de ácidos orgânicos em amostras de leite fermentado pelos grãos de kefir e do tibet utilizando técnicas voltamétricas e HPLC. São Carlos, 2006. Tese (Doutorado em química analítica). Universidade de São Paulo. Instituto de química de São Carlos.

McCLEMENTS, D.J. Advances in the application of ultrasound in food analysis and processing - Review. Trends in Food Science \& Technology. v. 6, p. 293-298, 1995. DOI: 10.1016/S0924-2244(00)89139-6

McCLEMENTS, D.J. Ultrasonic characterizatio of foods and drinks: principles, methods, and applications. Critical Reviews in Food Science and Nutrition, v. 37, n. 1, p. 1-46, 1997. DOI: 10.1080/10408399709527766 
PONSANO, H. G.; PERRI, S. H. V.; MADUREIRA, F. C. P.; PAULINO, R. Z.; CAMOSSI, L. G. Correlação entre métodos tradicionais e espectroscopia de ultra-som na determinação de características físico-químicas do leite. Arquivo Brasileiro de Medicina Veterinária e Zootecnia, v.59, n.4, p.1052-1057, 2007. DOI: 10.1590/S010209352007000400035

TRONCO, V. M. Manual para inspeção da qualidade do leite. 3. ed. Santa Maria: Ed. da Universidade Federal de Santa Maria. 2008

VENTUROSO, R. C.; ALMEIDA, K, E.; RODRIGUES, A, M.; DAMIN, M, R.;OLIVEIRA M. N. Determinação da composição físico-química de produtos lácteos: estudo exploratório de comparação dos resultados obtidos por metodologia oficial e ultra-som. Brazilian Journal of Pharmaceutical Sciences, v. 43, n. 4, 2007.

ZAFALON, L.F.; Como melhorar (e manter) a qualidade do leite?. A lavoura. p 15-19. abr 2011.

Trabalho selecionado para apresentação oral durante a VIII SETAL- Semana de Tecnologia de Alimentos- Câmpus Ponta Grossa- Universidade Tecnológica Federal do Paraná- 01 a 03 de junho de 2011. Suplemento especial da RBTA. 